\title{
Effect of age and moderate food restriction on insulin sensitivity in Wistar rats: role of adiposity
}

\author{
Fernando Escrivá, M Lucía Gavete, Yasmín Fermín ${ }^{1}$, Coralia Pérez ${ }^{1}$, Nilda Gallardo ${ }^{2}$, Carmen Alvarez, \\ Antonio Andrés ${ }^{2}$, Manuel $\operatorname{Ros}^{3}$ and José $\mathbf{M}$ Carrascosa ${ }^{1}$ \\ Departamento de Bioquímica, Facultad de Farmacia, Universidad Complutense, 28040 Madrid, Spain \\ ${ }^{1}$ Centro de Biología Molecular 'Severo Ochoa', Facultad de Ciencias, Universidad Autónoma, Campus de Cantoblanco, 28049 Madrid, Spain \\ ${ }^{2}$ Area de Bioquímica, Facultad de Químicas, Centro Regional de Investigaciones Biomédicas (CRIB), Universidad de Castilla La Mancha, 13071 Ciudad Real, \\ Spain \\ ${ }^{3}$ Facultad de Ciencias de la Salud, Universidad Rey Juan Carlos, 28922 Alcorcón, Madrid, Spain \\ (Requests for offprints should be addressed to J M Carrascosa; Email: jmcarrascosa@cbm.uam.es)
}

\begin{abstract}
Insulin resistance develops with ageing in humans and rodents. Here, we have studied the evolution of insulin sensitivity with ageing trying to discriminate the role of adiposity from that of ageing in this process. We performed oral glucose tolerance tests and determined overall and tissue-specific glucose utilization under euglycemic-hyperinsulinemic conditions in 3-, 8-, and 24-month-old rats fed ad libitum, and in 8- and 24-month-old rats after 3 months of calorie restriction. Body composition and adipocytederived cytokines such as leptin, resistin, and adiponectin were analyzed. Overall insulin sensitivity decreases with ageing. Calorie restriction improves global insulin sensitivity in 8- but not in 24-month-old rats. Insulin-stimulated glucose utilization in adipose tissues decreases in 8 months, while in oxidative muscles it reaches significance only in
\end{abstract}

older rats. Calorie restriction restores adipose tissue insulin sensitivity only in 8-month-old rats and no changes are observed in muscles of 24-month-old rats. Resistin and leptin increase with ageing. Food restriction lowers resistin and increases adiponectin in 8-month-old rats and decreases leptin in both ages. Visceral and total fat increase with ageing and decrease after calorie restriction. We conclude that accretion of visceral fat plays a key role in the development of insulin resistance after sexual maturity, which is reversible by calorie restriction. With aging, accumulation of retroperitoneal and total body fat leads to impaired muscle glucose uptake and to a state of insulin resistance that is difficult to reverse.

Journal of Endocrinology (2007) 194, 131-141

\section{Introduction}

Ageing is associated with a moderate decrease in peripheral insulin sensitivity in humans (De Fronzo 1981, Fink et al. 1983, Rowe et al. 1983) and rodents (Goodman et al. 1983, Narimiya et al. 1984, Nishimura et al. 1988, Escrivá et al. 1997). It is also associated with changes in body composition, especially in adipose tissue, making it difficult to evaluate the role of ageing by itself in the impairment of insulin action. Thus, while several reports have shown that decreased insulin sensitivity occurs in non-obese elderly humans (Fink et al. 1983, 1986), some have concluded that insulin resistance in the elderly derives from changes in body composition due to fat accumulation (Ferrannini et al. 1996, Basu et al. 2003). In this sense, it has been described that specific removal of epididymal and perirenal fat in 15-month-old F344/Brown Norway rats prevents the development of ageing-associated insulin resistance (Gabriely et al. 2002). On the other hand, adipose tissue is known to serve as an endocrine organ that liberates several adipokines which could modulate insulin action on target tissues (Ahima \& Flier 2000, Frühbeck et al. 2001). Therefore, we suggest that with ageing, the evolution of adiposity and different types of adipose tissue and their insulin sensitivity probably play a key role in the development of insulin resistance in different tissues and in the whole animal. Changes in adiposity by calorie restriction should modulate this insulin resistance.

Aged Wistar rats present a lower glucose disposal rate during euglycemic-hyperinsulinemic clamp than mature young rats, without changes in fasting plasma glucose and insulin concentrations (Nishimura et al. 1988, Escrivá et al. 1997), demonstrating a state of insulin resistance. However, this decrease in insulin sensitivity, far from being homogeneous, is tissue specific. Thus, while white adipose tissue, diaphragm, and soleus muscle present a clear decrease in glucose metabolic index under hyperinsulinemic conditions, other skeletal muscles like quadriceps remain insulin sensitive 
with ageing (Escrivá et al. 1997). In agreement with the resistance observed in adipose tissue, isolated adipocytes from aged rats show a decreased insulin response (Carrascosa et al. 1989, Molero et al. 1998, 2002, Villar et al. 2006).

Here, we have investigated the evolution of insulin sensitivity with ageing in adipose tissue and muscle and also the influence of adiposity on this process. In order to do this, we compared the overall and tissue-specific insulin sensitivity of 3-, 8-, and 24-month-old Wistar rats, as well as 8- and 24-month-old rats after 3 months of moderate food restriction which is sufficient to lower visceral adiposity to values even below those of mature 3-month-old rats fed ad libitum. The effects of ageing and food restriction on adipocyte-derived factors such as resistin, adiponectin, and leptin have also been analyzed.

\section{Materials and Methods}

\section{Animals}

Male Wistar rats of 3, 8, and 24 months old from our in-house colony (Centre of Molecular Biology, Madrid, Spain) were housed in climate-controlled quarters with a $12 \mathrm{~h}$ light cycle and fed standard laboratory chow and water available ad libitum. They were handled as per the European Union laws and National Institutes of Health (NIH) guidelines for animal care. Experimental procedures were approved by the Institutional Committee of Research Ethics.

\section{Food restriction}

Five- and 21-month-old rats were randomly selected to undergo a food restriction protocol as described earlier (Pérez et al. 2004). They were placed in individual cages and fed daily 18 and $21 \mathrm{~g}$ of chow respectively (equivalent to $\approx 80 \%$ of normal food intake). After 2 months of nutritional restriction, the rats showed a body weight equivalent to $\approx 85 \%$ of ad libitum fed aged-mates. They were weighed weekly and the amount of food provided was adjusted individually in order to maintain their body weight for one additional month. Food restricted rats were used at the age of 8 and 24 months respectively.

\section{Oral glucose tolerance test (OGTT)}

Overnight fasted rats were administered 30\% glucose solution intragastrically ( $2 \mathrm{~g} / \mathrm{kg}$ of body weight) and blood samples were taken from the tail vein before the glucose load $(t=0)$ and 15, 30, 60, and $120 \mathrm{~min}$ after glucose administration. Blood glucose was determined immediately using an Accutrend Glucose Analyser (Roche). Blood samples were centrifuged and plasma was frozen at $-70{ }^{\circ} \mathrm{C}$ until insulin estimation. Overall changes in glucose and insulin during OGTT were calculated as the area under the curve above the basal level ( $\Delta$ Glucose and $\Delta$ Insulin areas respectively).
The ratio of $\Delta$ Glucose area to $\Delta$ Insulin area was used as an index of whole body insulin sensitivity (Levy et al. 2002).

\section{Euglycemic-hyperinsulinemic clamp}

Overnight fasted rats were anesthetized with pentobarbital (4 mg/100 g of body weight) and tracheotomized to avoid respiratory problems. Blood samples were withdrawn from tail and glycemia was determined as indicated above. Insulin (Actrapid, Novo, Copenhagen, Denmark) was infused through a saphenous vein at a constant rate, without a priming dose, to reach values of 2 or $4 \mathrm{nmol} / \mathrm{h}$ per $\mathrm{kg}$ respectively, and a solution of $30 \%$ glucose was infused through the other saphenous vein at a variable rate to clamp blood glucose at the level present at the start of the experiment (Escrivá et al. 1997). This was achieved taking blood samples every $5 \mathrm{~min}$ and determining glucose concentration as indicated. Within $40 \mathrm{~min}$ of starting the clamp, plasma glucose and insulin remained constant without further adjusting the infusion rate. At this steady state, the overall glucose utilization reaches a constant value, which was further monitored for $60 \mathrm{~min}$. Glucose disposal rate (M) was determined from the rate of glucose infusion normalized to body weight and was used as an index of insulin sensitivity.

\section{Glucose utilization by individual tissues}

A bolus of $80 \mu \mathrm{Ci}$ of 2 -deoxy-D-[1- $\left.{ }^{3} \mathrm{H}\right]$ glucose (Amersham) was injected intravenously into rats either under steady-state conditions or not infused with insulin, to estimate basal glucose utilization. The concentration of glucose and radioactivity of 2 -deoxy-D- $\left[1-{ }^{3} \mathrm{H}\right]$ glucose were determined in blood samples taken every $5 \mathrm{~min}$. Measurements of plasma glucose and insulin before the injection of the radioactive bolus and at the end of the experiment $(60 \mathrm{~min})$ confirmed that steady-state conditions were maintained throughout the test. Rats were killed by cervical dislocation and pieces of the different tissues were rapidly removed and frozen until processing. Tissue digestion, determination of 2-deoxy-D-[1- $\left.{ }^{3} \mathrm{H}\right]$ glucose-6-phosphate, and estimation of the rate of glucose utilization was performed as reported previously (Ferré et al. 1985, Escrivá et al. 1992, 1997). Data are referred as the glucose metabolic index and can be considered as an index of glucose utilization at different insulin levels (Escrivá et al. 1997).

\section{Isolation of fat cells and determination of lipogenesis}

Rats were killed under $\mathrm{CO}_{2}$ atmosphere and visceral epididymal and retroperitoneal fat pads were removed and weighed to assess adiposity index (Li et al. 1997).

Adipocytes were prepared by digestion with collagenase as described by Molero et al. (1998). Isolated fat cells were suspended in Krebs-Ringer phosphate medium containing 3\% BSA, $2 \mathrm{mM}$ glucose, and $0 \cdot 25 \mu \mathrm{Ci} / \mathrm{ml}$ of $\left(\mathrm{U}_{-}{ }^{14} \mathrm{C}\right)$-glucose, in 
a proportion of $1 \mathrm{ml}$ cells per $3 \mathrm{ml}$ medium. The cells were incubated for $1 \mathrm{~h}$ at $37^{\circ} \mathrm{C}$ in the presence or absence of $20 \mathrm{nM}$ insulin. Incorporation of glucose into triglyceride and fatty acids was determined as described previously (Fain et al. 1967).

\section{Expression of hepatic PEPCK}

Total liver RNA was isolated using an RNase kit (Qiagen). The RNA (500 ng) was reverse transcribed and real-time quantitative PCR was performed on TaqMan 7000 sequence detection system (Applied Biosystems, Foster City, CA, USA) using SYBR Geen. Specific primers for PEPCK gene were designed with primer express 2.0 software (F, CGCTATGCGGCCCTT; R, AGCCAGTGCGCCAGGTACT) and $18 \mathrm{~S}$ rRNA was used as a control to normalize gene expression.

\section{Other determinations}

Plasma insulin, leptin, and adiponectin were determined using rat insulin, rat leptin, and mouse adiponectin RIA kits (Linco Research, St Charles, MO, USA) respectively. Resistin was assessed using a rat resistin ELISA kit (BioVendor, Brno, Czech Republic). Obesity Lee index was calculated as $10^{4} \times$ body weight $(\mathrm{g}) \times$ naso-anal length $\left(\mathrm{mm}^{-1}\right)$, as described previously (Li et al. 1997).

Total body fat and lean body mass were measured by dualenergy X-ray absorptiometry (DEXA; Norland XR-26, Venice, FL, USA).

For determining the triglyceride content of muscles, total lipids were extracted from $100 \mathrm{mg}$ of tissue (Cohen et al. 2002) and triglyceride content was measured using an enzymatic kit (Stanbio laboratory, Boerne, TX, USA).

\section{Statistical analysis}

Statistical comparisons to determine the effect of age and insulin treatment were done by one-way ANOVA using the Prophet software (BNN Systems and Technologies, Cambridge, MA, USA). When a significant effect of age or insulin was observed, the Duncan post hoc test was used to analyze differences between means. To compare food-restricted and ad libitum fed aged mates, the unpaired Student's $t$-test was used.

\section{Results}

\section{Characteristics of the animals}

Table 1 summarizes the characteristics of the five groups of rats used. In both 8- and 24-month-old rats, body weight increases progressively with ageing and the calorie restriction used in this study brings about $\sim 15 \%$ decrease in body weight. No significant effect of age on fasting plasma glucose and insulin was observed and calorie restriction decreased only the insulin concentration in 8-month-old rats.

Plasma adiponectin remained constant with ageing. Interestingly, food restriction elicited a significant increase in plasma adiponectin in 8-month but not in 24-month-old rats. Plasma leptin concentration increased progressively with ageing reaching values sixfold higher in 24-month-old rats than in 3-month-old rats. In 8-month-old rats, food restriction elicited a marked decrease of plasma leptin up to values significantly lower than those observed in younger rats. In 24-month-old rats, a more moderate decrease in leptin level was observed under food restriction. Plasma resistin increased significantly in 8-month-old rats; however, it is lower in 24-month-old rats. Food restriction significantly decreased circulating resistin at the age of 8 months but has no effect on older rats.

Changes in adiposity and body composition are shown in Table 2. One-way ANOVA indicates a significant effect of age on obesity Lee index $(P=0 \cdot 0082)$. Nevertheless, Lee index at the age of 24 months was well under that of young obese Wistar diabetic fatty rats (C Pérez and JM Carrascosa unpublished observations). Food restriction elicited a significant decrease of Lee index in both 8- and 24-month-old rats. The percent of visceral fat increased significantly up to the age of 8 months and remained constant thereafter. The weight of the two fat pads analyzed increased up to the age of 8 months, but only the retroperitoneal fat continued to increase up to 24 months. Calorie restriction decreased the adiposity index equally in 8- and 24-month-old rats. A similar decrease was observed in epididymal fat at both ages whereas the decrease in retroperitoneal fat was lower in 24-month-old rats. Lean body mass did not undergo significant changes either with ageing or with calorie restriction. In contrast, a significant increase in total and

Table 1 Characteristics of the rats. Data are the mean \pm s.E.M. of 10-20 separate determinations

Body weight (g)

Fasting plasma glucosa (mmol/l)

Fasting plasma insulin (nmol/l)

Fasting plasma adiponectin $(\mu \mathrm{g} / \mathrm{ml})$

Fasting plasma leptin $(\mathrm{ng} / \mathrm{ml})$

Fasting plasma resistin $(\mathrm{ng} / \mathrm{ml})$

\begin{tabular}{c}
3 months \\
\hline $383 \pm 8$ \\
$4 \cdot 5 \pm 0 \cdot 2$ \\
$0 \cdot 19 \pm 0 \cdot 02$ \\
$3 \cdot 1 \pm 0 \cdot 2$ \\
$4 \cdot 6 \pm 0 \cdot 5$ \\
$18 \cdot 0 \pm 2 \cdot 5$
\end{tabular}

8 months-FR

$431 \pm 4^{\mathrm{c}}$
$4 \cdot 6 \pm 0 \cdot 2$
$0 \cdot 09 \pm 0 \cdot 01^{\mathrm{c}}$
$4 \cdot 1 \pm 0 \cdot 3^{\mathrm{c}}$
$2 \cdot 0 \pm 0 \cdot 1^{\mathrm{c}}$
$17 \cdot 3 \pm 1 \cdot 0^{\mathrm{c}}$

24 months

$700 \pm 12^{\mathrm{b}}$
$5 \cdot 0 \pm 0 \cdot 1$
$0 \cdot 26 \pm 0 \cdot 02$
$3 \cdot 0 \pm 0 \cdot 2$
$27 \cdot 6 \pm 4 \cdot 0^{\mathrm{b}}$
$23 \cdot 2 \pm 1 \cdot 7^{\mathrm{d}}$

24 months-FR

$603 \pm 15^{c}$

$4 \cdot 5 \pm 0 \cdot 2$

$0 \cdot 23 \pm 0 \cdot 04$

$2 \cdot 9 \pm 0 \cdot 2$

$7 \cdot 1 \pm 1 \cdot 2^{\mathrm{C}}$

$24 \cdot 7 \pm 1 \cdot 6$

One-way ANOVA indicates a significant effect of age on body weight $(P=0 \cdot 001)$, plasma leptin $(P=0 \cdot 001)$ and resistin $(P=0 \cdot 0002)$, and no significant effect on plasma adiponectin, glucose and insulin levels $(P>0 \cdot 05)$. ${ }^{\mathrm{a}} P<0 \cdot 05$ versus 3 -month-old rats; ${ }^{\mathrm{b}} P<0.05$ versus 3 - and 8 -month-old rats; ${ }^{\mathrm{c}} P<0 \cdot 05$ versus same age fed ad libitum; ${ }^{\mathrm{d}}<<0.05$ versus 8 -month-old rats. FR, food restricted. 
Table 2 Changes in adiposity with age and calorie restriction. Data are the mean \pm S.E.M. of 4-10 separate determinations

Obesity Lee index

Adiposity index $(\%)$

Epididymal fat (g)

Retroperitoneal fat $(\mathrm{g})$

Total fat mass (\%)

Total fat mass (g)

Lean body mass $(\mathrm{g})$

Triglyceride content in soleus (mg/g of tissue)

Triglyceride content in quadriceps ( $\mathrm{mg} / \mathrm{g}$ of tissue)

\begin{tabular}{c}
3 months \\
\hline $301 \pm 1$ \\
$3 \cdot 2 \pm 0 \cdot 1$ \\
$4 \cdot 5 \pm 0 \cdot 2$ \\
$5 \cdot 2 \pm 0 \cdot 2$ \\
$7 \cdot 1 \pm 1 \cdot 6$ \\
$26 \cdot 5 \pm 5 \cdot 9$ \\
$340 \pm 15$ \\
$6 \cdot 9 \pm 1 \cdot 6$ \\
$2 \cdot 0 \pm 0 \cdot 2$
\end{tabular}

\begin{tabular}{c}
8 months-FR \\
\hline $289 \pm 1^{\mathrm{c}}$ \\
$1 \cdot 7 \pm 0 \cdot 1^{\mathrm{c}}$ \\
$4 \cdot 8 \pm 0 \cdot 5^{\mathrm{c}}$ \\
$2 \cdot 7 \pm 0 \cdot 5^{\mathrm{c}}$ \\
$16 \cdot 9 \pm 1 \cdot 4^{\mathrm{c}}$ \\
$73 \cdot 7 \pm 7 \cdot 2^{\mathrm{c}}$ \\
$332 \pm 5$ \\
$2 \cdot 9 \pm 0 \cdot 7$ \\
$3 \cdot 8 \pm 0 \cdot 8$
\end{tabular}

24 months-FR

$298 \pm 3^{\mathrm{c}}$
$2 \cdot 3 \pm 0 \cdot 1^{\mathrm{c}}$
$5 \cdot 4 \pm 0 \cdot 6^{\mathrm{c}}$
$8 \cdot 9 \pm 0 \cdot 6^{\mathrm{c}}$
$29 \cdot 7 \pm 1 \cdot 9$
$171 \cdot 7 \pm 16 \cdot 9^{\mathrm{c}}$
$388 \pm 9$
$6 \cdot 3 \pm 2 \cdot 9$
$4 \cdot 3 \pm 0 \cdot 8^{\mathrm{c}}$

One-way ANOVA indicates a significant effect of age on obesity Lee index $(P=0 \cdot 0082)$, adiposity index $(P=0 \cdot 001)$, epididymal $(P=0 \cdot 001)$ and retroperitoneal $(P=0 \cdot 0007)$ fat, percent $(P=0.001)$ and total fat mass $(P=0 \cdot 001)$, and triglyceride content in quadriceps $(P=0 \cdot 008)$. No significant effect on lean body mass, and triglyceride content in soleus muscle was observed $(P>0 \cdot 05)$. ${ }^{a} P<0.05$ versus 3 -month-old rats; ${ }^{b} P<0 \cdot 05$ versus 3 - and 8 -month-old rats; ${ }^{c} P<0 \cdot 05$ versus same age fed ad libitum. FR, food restricted.

percent fat was observed with ageing. Calorie restriction decreased total body fat in 8- and 24-month-old rats. However, when expressed in percent, this decrease was not significant in older rats.

Triglyceride content in soleus remained unchanged with ageing and food restriction. In quadriceps, a significant increase was observed in 24-month-old rats, that was reverted by calorie restriction (Table 2)

\section{Oral glucose tolerance}

Changes in glucose and insulin during OGTT are shown in Table 3. The increment of glucose was similar for the three age groups indicating that glucose tolerance was not modified during ageing. In contrast, the area under the curve for insulin in response to the glucose load increased progressively during ageing suggesting the development of peripheral insulin resistance. In food restricted rats, changes in blood glucose during OGTT were similar to that observed in their respective aged mates fed ad libitum, indicating that it did not alter the glucose tolerance in spite of the marked decrease in adiposity (Table 2). Nevertheless, the insulin needed to cope with the glucose load was significantly lower in 8-month-old rats and in 24-month-old rats, the increment in insulin during OGTT being similar to that of ad libitum fed aged mates. Insulin sensitivity index, calculated as the ratio of $\Delta$ Glucose area to $\Delta$ Insulin area, decreased between 3 and 8 months, and a further significant decrease was observed up to the age of 24 months. Calorie restriction induced a marked improvement of insulin sensitivity in 8-month-old rats but not in 24-monthold rats in spite of a similar change of adiposity in both groups.

\section{Euglycemic-hyperinsulinemic clamp}

Plasma glucose and insulin concentrations at steady state, 45 min after starting the clamp, are shown in Table 4. Glucose concentrations were clamped at similar levels in all groups within the physiological range. Plasma insulin concentrations at steady state were significantly elevated in both 8 - and 24-month-old rats at the highest insulin infusion rate and were not altered by calorie restriction.

The rate of glucose infusion per kilogram of body weight necessary to maintain blood glucose concentrations during the clamp decreased significantly with age at both insulin infusion rates (Fig. 1 and Table 4). In 8-month-old rats, this decrease was significant only at the highest insulin infusion rate, whereas in 24-month-old rats, a significantly lower glucose infusion was required for both insulin doses.

In 8-month-old rats, calorie restriction significantly increased the glucose disposal rate at both insulin infusion rates. In contrast, in 24-month-old rats, a significant increase was observed only at the lower insulin dose, whereas the glucose utilization at the highest dose of insulin was similar to that observed in ad libitum fed aged mates (Fig. 1 and Table 4).

Table 3 Variations of glucose and insulin concentrations in blood during oral glucose tolerance test. Data are mean \pm s.E.M. of $6-7$ rats per group

$\Delta$ Glucose area $(\mathrm{mM} \times \min )$

Age (months)
3
8
8 -FR
24
$24-F R$

$429 \pm 50$
$396 \pm 32$
$363 \pm 44$
$429 \pm 77$
$500 \pm 50$

$\Delta$ Insulin area $(\mathrm{nM} \times \min )$

$4 \cdot 8 \pm 1 \cdot 1$
$13 \cdot 8 \pm 2 \cdot 1^{\mathrm{a}}$
$2 \cdot 4 \pm 0 \cdot 3^{\mathrm{c}}$
$27 \cdot 6 \pm 4 \cdot 0^{\mathrm{b}}$
$25 \cdot 4 \pm 4 \cdot 3$
Insulin sensitivity index

$$
\begin{gathered}
91 \pm 13 \\
28 \pm 2^{a} \\
205 \pm 35^{c} \\
18 \cdot 6 \pm 3 \cdot 0^{b} \\
22 \cdot 9 \pm 3 \cdot 3
\end{gathered}
$$

$\Delta$ Glucose area, $\Delta$ Insulin area and Insulin sensitivity index were determined as indicated in Materials and Methods. ${ }^{\text {a }} P<0 \cdot 05$ significantly different from 3 month-old rats; ${ }^{\mathrm{b}} \mathrm{P}<0.05$ significantly different from 3 - and 8 -month-old rats; ${ }^{\mathrm{C}} \mathrm{P}<0.05$ significantly different from same age fed ad libitum. FR, food restricted. 
Table 4 Metabolic characteristics of the rats during euglycemic-hyperinsulinemic clamp. Data are the mean \pm S.E.M. of 5-6 different clamps performed with each group of rats

\begin{tabular}{|c|c|c|c|}
\hline & \multirow[b]{2}{*}{ Age (months) } & \multicolumn{2}{|c|}{ Insulin infusion rate $(\mathrm{nmol} / \mathrm{h}$ per $\mathrm{kg})$} \\
\hline & & 2 & 4 \\
\hline \multirow[t]{5}{*}{ Steady state plasma glucose $(\mathrm{mmol} / \mathrm{l})$} & 3 & $5 \cdot 3 \pm 0 \cdot 3$ & $5 \cdot 1 \pm 0 \cdot 5$ \\
\hline & 8 & $4 \cdot 4 \pm 0 \cdot 3$ & $5 \cdot 0 \pm 0 \cdot 4$ \\
\hline & 8-FR & $5 \cdot 7 \pm 0 \cdot 7$ & $5 \cdot 0 \pm 0 \cdot 4$ \\
\hline & 24 & $5 \cdot 4 \pm 0 \cdot 5$ & $5 \cdot 4 \pm 0 \cdot 2$ \\
\hline & $24-F R$ & $5 \cdot 2 \pm 0 \cdot 3$ & $5 \cdot 1 \pm 0 \cdot 2$ \\
\hline \multirow[t]{5}{*}{ Steady state plasma insulin $(\mathrm{nmol} / \mathrm{l})$} & 3 & $1 \cdot 1 \pm 0 \cdot 2$ & $2 \cdot 3 \pm 0 \cdot 8$ \\
\hline & 8 & $1 \cdot 0 \pm 0 \cdot 4$ & $4 \cdot 8 \pm 0 \cdot 7^{a}$ \\
\hline & 8-FR & $1 \cdot 1 \pm 0 \cdot 4$ & $4 \cdot 2 \pm 0 \cdot 7$ \\
\hline & 24 & $1 \cdot 5 \pm 0 \cdot 4$ & $5 \cdot 0 \pm 0 \cdot 2^{a}$ \\
\hline & 24-FR & $2 \cdot 1 \pm 0 \cdot 5$ & $6 \cdot 1 \pm 1 \cdot 0$ \\
\hline \multirow[t]{5}{*}{$\mathrm{M}(\mu \mathrm{mol} / \mathrm{min} / \mathrm{kg})$} & 3 & $86 \cdot 6 \pm 2 \cdot 8$ & $117 \cdot 8 \pm 5 \cdot 5$ \\
\hline & 8 & $78 \cdot 3 \pm 7 \cdot 2$ & $89 \cdot 4 \pm 3 \cdot 3^{a}$ \\
\hline & 8-FR & $106 \cdot 7 \pm 9 \cdot 4^{\mathrm{C}}$ & $130 \cdot 5 \pm 5 \cdot 5^{\mathrm{c}}$ \\
\hline & 24 & $62 \cdot 8 \pm 2 \cdot 8^{\mathrm{b}}$ & $81 \cdot 1 \pm 6 \cdot 7^{\mathrm{a}}$ \\
\hline & $24-F R$ & $88 \cdot 3 \pm 3 \cdot 9^{\mathrm{C}}$ & $91 \cdot 7 \pm 5 \cdot 0$ \\
\hline
\end{tabular}

One-way ANOVA indicates a significant effect of age on steady state plasma insulin at the highest infusion rate $(P=0 \cdot 049)$, and on $(M)$ at both insulin doses $(P=$ $0 \cdot 0001$ and 0.0003 for 2 and $4 \mathrm{nmol} / \mathrm{h}$ per $\mathrm{kg}$ of infused insulin respectively). $\mathrm{M}$, glucose disposal rate, determined from the rate of glucose infusion normalized to body weight. ${ }^{a} P<0.05$ versus 3 -month-old rats; ${ }^{b} P<0.05$ versus 3 - and 8 -month-old rats; ${ }^{c} P<0.05$ versus same age fed ad libitum. FR, food restricted.

\section{Expression of hepatic PEPCK}

Changes in glucose utilization could be influenced by alterations in the hepatic gluconeogenic function. Variations in liver gluconeogenesis depend mainly on the gluconeogenic enzyme PEPCK whose expression has become an important marker for hepatic gluconeogenesis (Hanson \& Reshef 1997, Hakimi et al. 2005). Determination of PEPCK expression by real-time PCR indicated that neither age nor calorie restriction significantly altered the level of expression of the enzyme (data not shown).

\section{Glucose utilization in specific tissues}

Figure 2 shows that in both retroperitoneal and epididymal white adipose tissue, insulin stimulates the glucose uptake in 3-month-old rats approximately six and threefold respectively. Insulin also stimulates the glucose utilization $(P=0 \cdot 023)$ significantly in retroperitoneal adipose tissue of 8-month-old rats However, the stimulatory effect of the hormone and the maximal glucose uptake were significantly lower in 8-month old than in 3-month-old rats. In 24-month-old rats, a lower insulin-stimulated glucose uptake was observed.

$$
3 \text { months } \quad 8 \text { months } \quad 8 \text { months-FR } 24 \text { months } 22 \text { months-FR }
$$

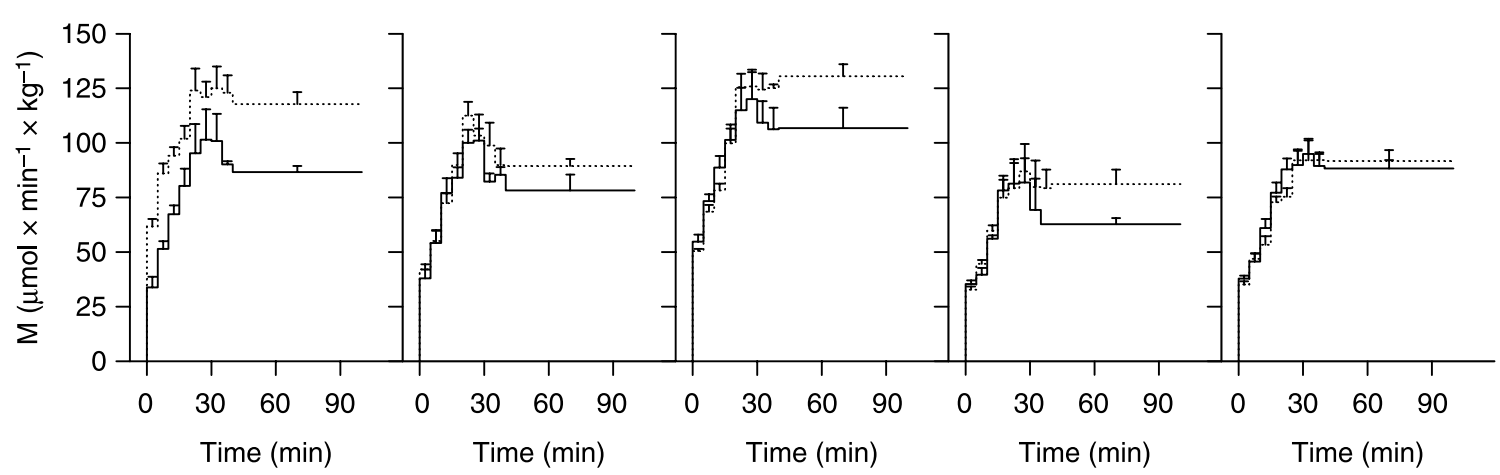

Figure 1 Glucose infusion rate during euglycemic-hyperinsulinemic clamp. Anesthetized overnight fasted rats were infused with insulin as indicated in Materials and Methods, to reach values of 2 ( - ) or 4 (...) nmol/h per $\mathrm{kg}$ respectively and a solution of $30 \%$ glucose was infused through the other saphenous vein at variable rate to clamp blood glucose at the level present at the start of the experiment (see Materials and Methods). Glucose infusion rate was adjusted every 5 min after determining blood glucose concentration as indicated in Materials and Methods. Within 40 min of start of the clamp, glucose concentration remained constant without further adjusting the infusion rate. Blood glucose was monitored for further $60 \mathrm{~min}$. Data at plateau represent the overall glucose disposal rate $(M)$, are the mean \pm S.E.M. of 5-6 different clamps performed with each group of rats, and are expressed as $\mu \mathrm{mol}$ of glucose $\times \mathrm{min}^{-1} \times \mathrm{kg}^{-1}$ of body weight. Statistical comparisons are shown in Table 4 . FR, food restricted. 


\section{A} Insulin infusion rate $\left(\mathrm{nmol} \times \mathrm{h}^{-1} \times \mathrm{kg}^{-1}\right)$

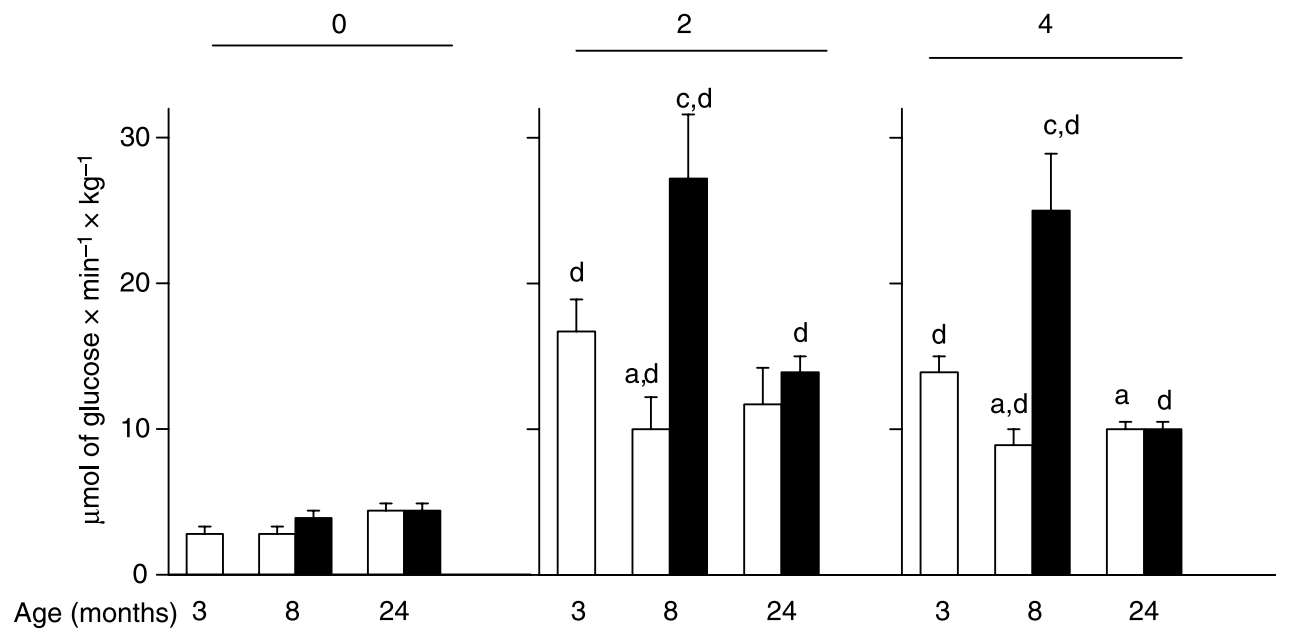

B Insulin infusion rate $\left(\mathrm{nmol} \times \mathrm{h}^{-1} \times \mathrm{kg}^{-1}\right)$

0

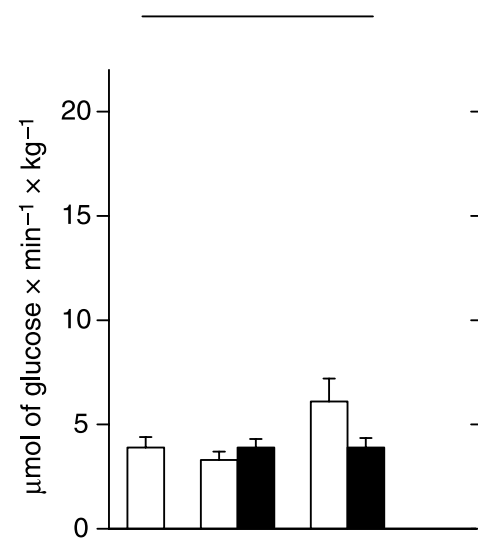

Age (months) 3

8

24
2
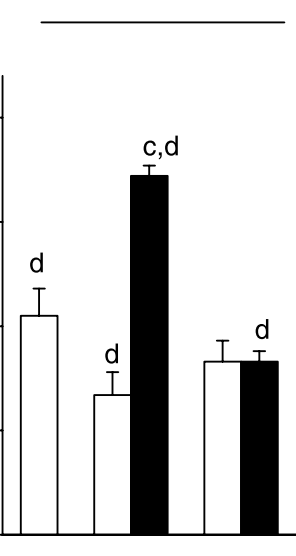

24

8

Figure 2 Glucose metabolic index of retroperitoneal and epididymal adipose tissues during euglycemichyperinsulinemic clamp. Glucose utilization was estimated under euglycemic conditions in 3-, 8-, and 24-month-old rats fed ad libitum and in 8- and 24-month-old rats after 3 months of moderate calorie restriction, as indicated in Materials and Methods. Data are expressed as $\mu$ mol of glucose $\times \mathrm{min}^{-1} \times \mathrm{kg}^{-1}$ of tissue and are the mean \pm s.E.M. of 5-8 independent determinations in each case. White bars, rats fed ad libitum; Black bars, rats under calorie restriction. (A), Retroperitoneal white adipose tissue; (B), Epididymal white adipose tissue. ${ }^{\mathrm{a}} P<0.05$ versus 3 -month-old rats; ${ }^{\mathrm{b}} P<0.05$ versus 3 - and 8 -month-old rats; ${ }^{\mathrm{C}} P<0.05$ versus same age fed ad libitum; ${ }^{\mathrm{d}} P<0.05$ versus basal; ${ }^{\mathrm{e}} P<0.05$ versus basal and $2 \mathrm{nmol} / \mathrm{h}$ per $\mathrm{kg}$.

The stimulatory effect of insulin on glucose utilization was also lower in epididymal white adipose tissue of 8 - and 24-month-old rats (2- and 1-4-fold respectively) than in 3-month-old rats (3-fold). Thus, both adipose tissues develop a marked insulin resistance at 8 months and remain poorly sensitive in 24-month-old rats.
In 8-month-old rats, calorie restriction increases the insulin stimulation of glucose uptake in both adipose tissues and insulin infusion rates up to values even higher than those observed in young rats. In contrast, no improvement of insulin action was observed in adipose tissues of 24-month-old rats under calorie restriction when compared with ad libitum fed age-matched rats. 
In soleus and diaphragm (Fig. 3), a significant agedependent decrease of glucose uptake at both insulin infusion rates was observed (in soleus, $P=0.004$ and $0 \cdot 048$, and in the diaphragm, $P=0 \cdot 045$ and $0 \cdot 008$, for 2 and $4 \mathrm{nmol} / \mathrm{h}$ per $\mathrm{kg}$ insulin infusion rate respectively). Nevertheless, the post hoc test used indicates that this decrease is only significant for 24-month-old rats whereas glucose uptake in rats aged 8 months is not significantly different from that of 3-month-old rats. Calorie restriction improved the insulin effect on glucose utilization in 8- and 24-monthold rats at the lower insulin infusion rate, but did not alter the glucose utilization of both tissues at the highest insulin level. Thus, calorie restriction did not increase the contribution to overall glucose disposal of soleus and diaphragm of 24-month-old rats under hyperinsulinemic conditions.

Concerning quadriceps muscle, data in Fig. 3 show that glucose uptake is not significantly modified during ageing at any of the insulin infusion rates used, indicating that this tissue does not contribute to the decreased overall glucose utilization of 8 - and 24-month-old rats. In food restricted 8-month-old rats, a lower glucose uptake is observed only in the absence of insulin infusion, whereas in food-restricted 24-month-old rats, a significant increase of glucose uptake occurs at submaximal insulin concentrations, suggesting an improvement of insulin sensitivity in this tissue. However, maximal glucose uptake was not altered by food restriction in both 8 - and 24-month-old rats.

In agreement with previous reports (Escrivá et al. 1997), glucose utilization by brain and lung of 3-month-old rats was not stimulated under hyperinsulinemic conditions (data not shown) confirming the specificity of the former insulin effects.

\section{Insulin action on isolated adipocytes}

We studied the insulin responsiveness of isolated adipocytes from rats of different groups (Table 5). The rate of incorporation of glucose into triglyceride in the absence of insulin remains unchanged with age. In contrast, incorporation of glucose into triglyceride-fatty acids is significantly lower in 8- and 24-month-old rats. Food restriction elicited a marked increase in basal lipogenic activity in both 8 - and 24-month-old rats. The stimulation of lipogenesis by insulin declined in fat cells of 8-monthold rats when compared with 3-month-old rats. However, no further decline was observed up to the age of 24 months. Calorie restriction induced a marked increase in the lipogenic action of insulin on adipocytes of 8 -monthold rats that become even more sensitive than fat cells of 3 -month-old rats. Calorie restriction also improved insulin sensitivity in adipocytes of 24-month-old rats but to a lower extent than in food restricted 8-month-old rats.

\section{Discussion}

Using two different in vivo approaches, we show here that overall insulin sensitivity decreases during ageing in the Wistar rat. This occurs in spite of normal fasting blood glucose and insulin concentrations and without developing glucose intolerance as observed in OGTT. The data in this work indicate that the main decrease in insulin sensitivity occurs between 3 and 8 months of age but declines further up to the age of 24 months.

Studies focused to examine the effects of ageing on insulin action are fraught with the difficulty of discriminating the effect of age by itselffrom that of the age-associated changes in body composition. Although there is a significant increase in body weight during ageing, obesity Lee index of old rats is markedly lower than that observed in morbid obese Wistar Diabetic Fatty rats. Our data show that the decrease of insulin sensitivity up to 8 months of age is paralleled by a significant increase in visceral and total fat mass. Between 8 and 24 months of age insulin sensitivity decreases further without significant changes in percent visceral adiposity. However, it should be noted that rats grow throughout their life span. Thus, even though no changes in adiposity index are observed after 8 months, there is a significant increase in retroperitoneal and total fat with ageing, which may be related to the decline of insulin sensitivity after 8 months of age. In contrast, lean body mass does not change significantly with ageing.

The data obtained from food-restricted rats also point to the relevance of retroperitoneal fat in the development of insulin resistance in older rats. Thus, under moderate calorie restriction, both 8- and 24-month-old rats exhibit similar and significant decrease in percent visceral adiposity and total fat mass, reaching values of the former even lower than those of control young rats. However, only in the case of 8-month-old rats, a marked improvement of whole body insulin sensitivity index was observed. Nevertheless, the data clearly shows that there is a major difference in the reduction of retroperitoneal fat, which remains markedly higher in 24-month-old rats. This suggests that the decline in insulin sensitivity in early adulthood could be due to fat accumulation and can be reversed by lowering overall adiposity. However, beyond this age limit, the sustained increase in retroperitoneal fat and its refractoriness to decrease even under food restriction might bring about damages in some tissues, leading to a state of irreversible insulin resistance.

Other authors have reported that surgical removal of visceral fat prevents the age-associated decline in insulin sensitivity (Gabriely et al. 2002). However, one report (Catalano et al. 2005) suggests that intra-abdominal adiposity accounts for only $30-40 \%$ of the changes in hepatic and peripheral insulin resistance associated with ageing in BN/ F344 rats. Our data here indicates that both retroperitoneal and non-visceral fat play a role in the changes of insulin sensitivity with age and food restriction. 
SOLEUS

Insulin infusion rate $\left(\mathrm{nmol} \times \mathrm{h}^{-1} \times \mathrm{kg}^{-1}\right)$

0

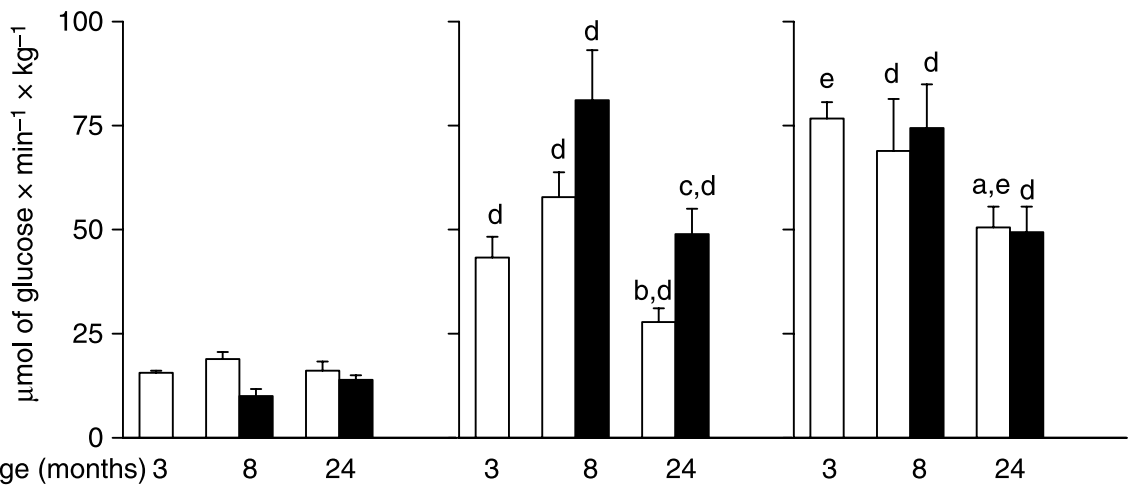

DIAPHRAGM

Insulin infusion rate $\left(\mathrm{nmol} \times \mathrm{h}^{-1} \times \mathrm{kg}^{-1}\right)$

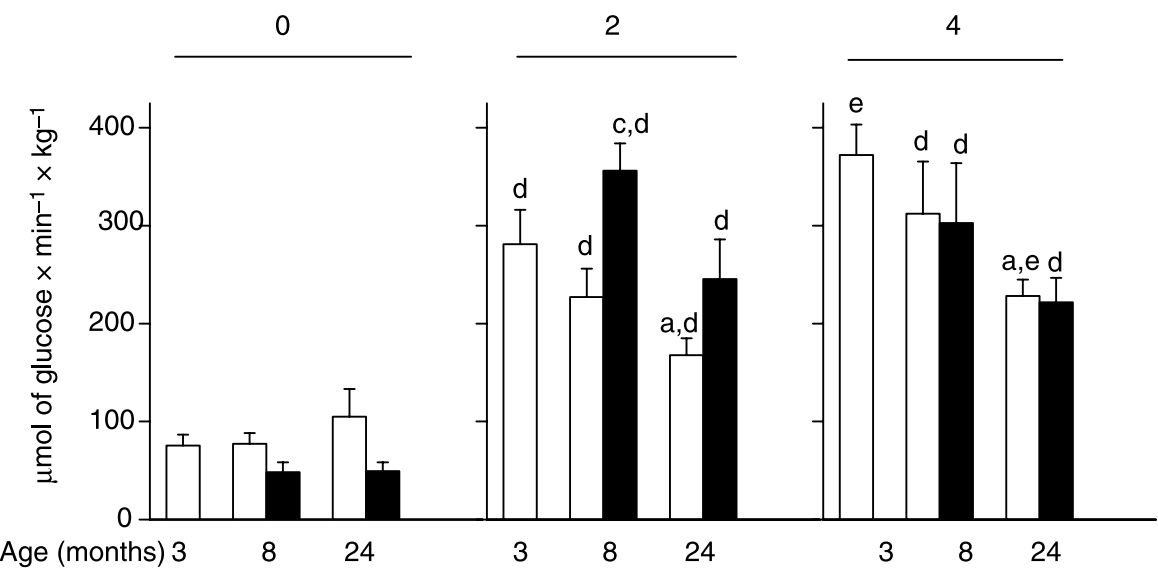

QUADRICEPS Insulin infusion rate $\left(\mathrm{nmol} \times \mathrm{h}^{-1} \times \mathrm{kg}^{-1}\right)$

0

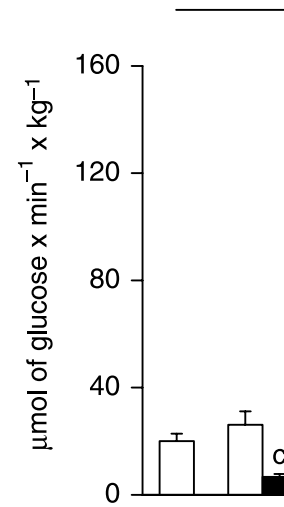

Age (months) 3
2

4

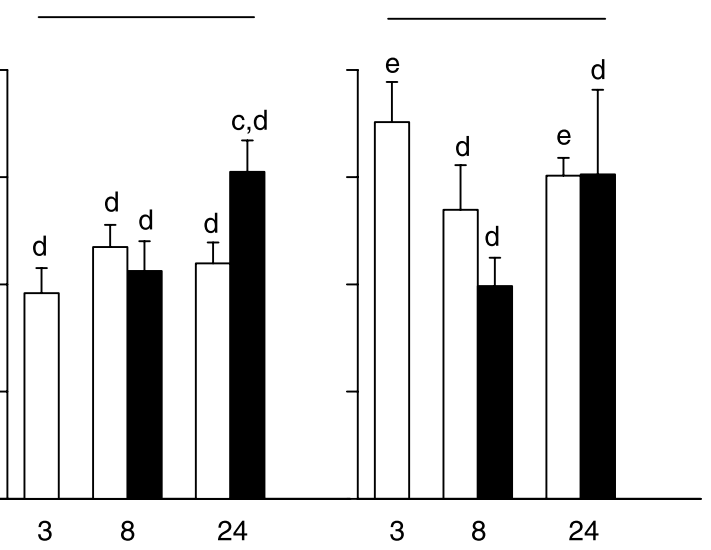


Table 5 Insulin responsiveness of isolated adipocytes: effect of age and food restriction. Data are mean \pm S.E.M. of $6-8$ rats per group

\section{Glucose incorporation into}

\begin{tabular}{|c|c|c|c|c|c|c|}
\hline & \multicolumn{3}{|l|}{ Triglyceride } & \multicolumn{3}{|l|}{ Fatty acids } \\
\hline & $\begin{array}{l}\text { Basal } \\
\left(\mathrm{nmol} / 10^{5} \mathrm{cell} / \mathrm{s} / \mathrm{h}\right)\end{array}$ & $\begin{array}{l}\text { Insulin } \\
\left(\mathrm{nmol} / 10^{5} \text { cells/h) }\right.\end{array}$ & $\%$ & $\begin{array}{l}\text { Basal } \\
\left(\mathrm{nmol} / 10^{5} \text { cells } / \mathrm{h}\right)\end{array}$ & $\begin{array}{l}\text { Insulin } \\
\left(\mathrm{nmol} / 10^{5} \text { cells } / \mathrm{h}\right)\end{array}$ & $\%$ \\
\hline 3-months & $2 \cdot 05 \pm 0 \cdot 22$ & $3 \cdot 53 \pm 0.35$ & $174 \pm 10$ & $0 \cdot 52 \pm 0 \cdot 12$ & $1 \cdot 33 \pm 0.35$ & $267 \pm 23$ \\
\hline 8-months & $2 \cdot 16 \pm 0 \cdot 28$ & $2 \cdot 90 \pm 0 \cdot 38$ & $136 \pm 12^{\mathrm{a}}$ & $0 \cdot 14 \pm 0 \cdot 03^{\mathrm{a}}$ & $0 \cdot 18 \pm 0 \cdot 03^{a}$ & $133 \pm 9^{\mathrm{a}}$ \\
\hline 8-months FR & $8.01 \pm 1 \cdot 43^{\mathrm{C}}$ & $23 \cdot 8 \pm 4 \cdot 8^{\mathrm{C}}$ & $309 \pm 33^{c}$ & $0 \cdot 86 \pm 0 \cdot 11^{\mathrm{c}}$ & $3 \cdot 13 \pm 0 \cdot 44^{\mathrm{C}}$ & $442 \pm 82^{\circ}$ \\
\hline 24-months & $2 \cdot 21 \pm 0 \cdot 54$ & $2 \cdot 69 \pm 0.59^{\mathrm{a}}$ & $126 \pm 6^{a}$ & $0 \cdot 13 \pm 0.01^{\mathrm{a}}$ & $0 \cdot 20 \pm 0 \cdot 03^{a}$ & $149 \pm 12^{\mathrm{a}}$ \\
\hline $\begin{array}{l}\text { 24-months } \\
\text { FR }\end{array}$ & $8 \cdot 30 \pm 0 \cdot 20^{c}$ & $13 \cdot 4 \pm 2 \cdot 2^{\mathrm{c}}$ & $163 \pm 31^{c}$ & $0.90 \pm 0.04^{\mathrm{c}}$ & $2 \cdot 03 \pm 0 \cdot 41^{\mathrm{c}}$ & $236 \pm 57^{c}$ \\
\hline
\end{tabular}

Adipocytes were incubated as indicated in Materials and Methods. ${ }^{\mathrm{a}} P<0 \cdot 05$, significantly different from 3-month-old rats; ${ }^{\mathrm{c}} P<0 \cdot 05$, significantly different from same age fed ad libitum. One-way ANOVA indicates significant effect of age on glucose incorporation into triglyceride in presence of insulin $(P=0 \cdot 033)$. FR, food restricted.

The data in this work, with respect to the insulin target tissues, demonstrate that the glucose metabolic index of both adipose tissues analyzed is lower in 8- and 24-month-old rats than in younger rats. These data agree with the decreased insulin effect on lipogenesis observed in isolated adipocytes and indicates that this insulin-resistant state develops early after sexual maturation. Impaired insulin action in adipose tissue could represent an early step leading to the overall insulin resistance characteristic of aged and/or obese rats (Smith 2002). Moreover, recent in vitro studies have demonstrated that adipocyte-conditioned medium impairs insulin signaling in skeletal muscle cells (Dietze et al. 2004) and hepatocytes (Wang et al. 2006a). The data presented herein indicates that insulin resistance in oxidative muscles such as soleus and diaphragm develops later than in adipose tissue, suggesting that it could be a secondary effect caused by the prolonged alteration of adipose tissue insulin sensitivity. Interestingly, changes in muscle insulin sensitivity with ageing and calorie restriction seem to be unrelated to the amount of muscle triglyceride. Thus, triglyceride content is similar in the soleus of the five groups of rats tested that show differences in insulin response, whereas in quadriceps no insulin resistance is observed, in spite of an increase of triglyceride content with ageing. Quadriceps muscle is mainly constituted by type $2 \mathrm{a}$ and $2 \mathrm{~b}$ fibers, which are mainly glycolytic and have a low capacity for using fatty acids as fuel, a fact that might explain the accumulation of triglycerides in this tissue in 24-month-old rats, which are characterized by increased serum triglyceride concentration (Escrivá et al. 1997). As reported by others (Kiens 2006, Kraegen et al. 2006), muscle insulin resistance is rather associated with cellular levels of malonyl-CoA, fatty acyl CoA, diacylglycerol, or ceramide, than with triglyceride accumulation. Thus, more experimental work is needed to clarify the differences in mechanism underlying the differences in insulin sensitivity between oxidative and glycolytic muscles with ageing.

The data in this work reveal that calorie restriction induces a marked increase in glucose utilization under hyperinsulinemic conditions in white adipose tissue of 8-month-old rats but not in 24-month-old rats. Beyond the quantitative contribution of adipose tissue to overall glucose disposal, this seems to contrast with the partial improvement of insulindependent lipogenic activity observed in isolated adipocytes from food restricted 24-month-old rats. However, glucose metabolic index is an in vivo estimation and some circulating adipokines could be influencing adipose tissue insulin sensitivity in vivo (see below). In soleus and diaphragm of 24-month-old rats, calorie restriction increases the glucose utilization at submaximal insulin levels but not at saturating insulin concentrations indicating that insulin resistance still persists in these tissues after calorie restriction. These data are also consistent with the absence of effect of calorie restriction on maximal overall glucose disposal rate, but a significant increase at submaximal insulin levels is observed in 24-month-old rats. On the other hand, although the data of PEPCK expression do not suggest significant changes in liver gluconeogenesis, it cannot be ruled out that alteration in liver insulin sensitivity results in changes in hepatic glucose output that may contribute to alter the whole body glucose disposal rate during ageing and calorie restriction.

Ageing is associated with fat mass accretion (Nishimura et al. 1988) and long-term changes in circulating adipokines could modulate insulin sensitivity. High levels of adiponectin have been associated with increased insulin sensitivity and, in situations of insulin resistance a low concentration of adiponectin has been observed (Chandran et al. 2003).

Figure 3 Glucose metabolic index of muscle tissue during euglycemic-hyperinsulinemic clamp. Glucose utilization was estimated as indicated in Fig. 1. Data are expressed as $\mu \mathrm{mol}$ of glucose $\times \mathrm{min}^{-1} \times \mathrm{kg}^{-1}$ of tissue and are the mean \pm s.E.M. of 5-8 independent determinations in each case. White bars, rats fed ad libitum; Black bars, rats under calorie restriction. Top, Soleus; Middle, Diaphragm; bottom, Quadriceps. a $P<0.05$ versus 3 -month-old rats; ${ }^{\mathrm{b}} P<0.05$ versus 3 - and 8 -month-old rats; ${ }^{\mathrm{c}} P<0.05$ versus same age fed ad libitum; ${ }^{\mathrm{d}} P<0.05$ versus basal; ${ }^{\mathrm{e}} P<0.05$ versus basal and $2 \mathrm{nmol} / \mathrm{h}$ per $\mathrm{kg}$. ${ }^{\mathrm{a}} P<0.01$ significantly different from 3 -month-old rats; ${ }^{\mathrm{b}} P<0 \cdot 05$ significantly different from 8 -month-old rats; ${ }^{c} P<0 \cdot 01$ significantly different from same age fed ad libitum. 
The data in this work show that plasma adiponectin remains unchanged with ageing suggesting that it does not play a role in the development of age-associated insulin resistance. Recent data have indicated that it is the high molecular weight adiponectin multimer, which is mainly associated with increased insulin sensitivity (Lara-Castro et al. 2006) and its formation depends on hydroxylation and glycosylation of four conserved lysine within the collagenous domain (Wang et al. 2006b). Thus, it remains possible that despite unchanged total amount of plasma adiponectin with ageing, an impaired lysine hydroxylation and/or glycosylation leads to lower levels of the insulin sensitizing adiponectin multimer in aged rats. Interestingly, a significant increase of adiponectin is observed only in 8-month-old rats after calorie restriction, a fact that might explain the differential effect of calorie restriction on insulin sensitivity at the two different ages.

Resistin causes insulin resistance in normal mice (Steppan et al. 2001) and chronic hyperresistinemia leads to insulin resistance in muscle, liver, and adipose tissue (Muse et al. 2004, Rangwala et al. 2004, Satch et al. 2004). The observed increase in plasma resistin in 8-month-old rats parallels the development of insulin resistance and its decrease in food restricted rats is associated with a marked improvement in insulin sensitivity. Thus, it could be speculated that resistin plays a role in the development of insulin resistance at early ageing. In contrast, in 24-month-old rats circulating resistin decreased and food restriction did not modify insulin concentration in plasma, in agreement with the absence of insulin sensitivity improvement after calorie restriction in these rats.

The increase in serum leptin with ageing observed here could explain the decrease in insulin sensitivity of adipose tissue in aged rats (Pérez et al. 2004). Although leptin is known to promote insulin sensitivity in muscle, aged rats show central leptin resistance (Fernández-Galaz et al. 2002), which could reduce the efficacy of leptin action on muscle through the central nervous system. After calorie restriction plasma leptin partially decreases in 24-month-old rats. However, the recovery of central leptin action could prevent the improvement of adipose tissue insulin sensitivity and might lead to a persistent state of overall insulin resistance.

To summarize, our data demonstrates that there is an early development of overall insulin resistance up to the age of 8 months in Wistar rats, the adipose tissue being the first of the tissues studied herein in developing insulin resistance. This could be mediated by increased plasma leptin and resistin concentrations, as well as overall fat accretion. Moderate calorie restriction reduces the amount of fat and improves insulin sensitivity in association with increased plasma adiponectin and lowered leptin and resistin levels. At more advanced age, insulin resistance also develops in some muscles and calorie restriction is unable to restore neither overall insulin sensitivity nor the insulin effects on adipose tissue and insulin-resistant muscles. It can thus be postulated that the persistent changes in adiposity, especially in retroperitoneal fat, associated with ageing could lead to irreversible harm in insulin target tissues resulting in insulin resistance. Although adipokines are candidates to mediate some of these effects, this issue requires further study. The data presented herein point to the relevance of adipose tissue as primary site of impairment of insulin sensitivity during ageing in the rat and suggest that an early recovery of adipose tissue insulin sensitivity is necessary for the effectiveness of moderate calorie restriction on the insulin action on the whole.

\section{Acknowledgements}

This work was supported by grants BFI2002-04030, BFI20020253 and BFU2005-07647 (Ministerio de Ciencia y Tecnología, Spain), 08.6/0009/2001 (Comunidad de Madrid, Spain), and ISCIII-RETIC RD06 (Ministerio de Sanidad y Consumo, Spain). The Centro de Biología Molecular is the recipient of institutional aid from the Ramón Areces Foundation. C P was a recipient of a fellowship from the Mutis Program (Spain). N G was supported by EI04-004 grant from Consejería de Sanidad (JCCM). Thanks are due to Dr L Gómez-Pellico and Dr R Rodríguez (Universidad de Alcalá de Henares, Madrid, Spain) for their help in determination of body composition by DEXA. The authors declare that there is no conflict of interest that would prejudice the impartiality of this scientific work.

\section{References}

Ahima RS \& Flier JS 2000 Adipose tissue as an endocrine organ. Trends in Endocrinology and Metabolism 11 327-332.

Basu R, Breda E, Oberg AL, Powell CC, Dalla Man C, Basu A, Vittone JL, Klee GG, Arora P, Jensen MD et al. 2003 Mechanisms of the age-associated deterioration in glucose tolerance. Diabetes 52 1738-1748.

Carrascosa JM, Ruiz P, Martínez C, Pulido JA, Satrústegui J \& Andrés A 1989 Insulin receptor kinase activity in rat adipocytes is decreased during aging. Biochemical and Biophysical Research Communications $160303-309$.

Catalano KJ, Bergman RN \& Ader M 2005 Increased susceptibility to insulin resistance associated with abdominal obesity in aging rats. Obesity Research 13 11-20.

Chandran M, Philips SA, Ciaraldi T \& Henry RR 2003 Adiponectin: more than just another fat cell hormone? Diabetes Care 26 2442-2450.

Cohen P, Miyazaki M, Socci ND, Hagge-Greenberg A, Liedtke W, Soukas AA, Sharma R, Hudgins LC, Ntambi JM \& Friedman JM 2002 Role for stearoylCoA desaturase-1 in leptin-mediated weight loss. Science 297 240-243.

Dietze D, Ramrath S, Ritzeler O, Tennagels N, Haunes H \& Eckel J 2004 Inhibitor $\kappa \mathrm{B}$ kinase is involved in the paracrine crosstalk between human fat and muscle cells. International Journal of Obesity 28 985-992.

Escrivá F, Rodríguez C, Cacho J, Alvarez C, Portha B \& Pascual-Leone AM 1992 Glucose utilization and insulin action in adult rats submitted to prolonged food restriction. American Journal of Physiology 263 E1-E7.

Escrivá F, Agote M, Rubio E, Molero JC, Pascual-Leone AM, Andrés A, Satrústegui J \& Carrascosa JM 1997 In vivo insulin-dependent glucose uptake of specific tissues is decreased during aging of mature Wistar rats. Endocrinology 138 49-54.

Fain JN, Reed N \& Saperstein R 1967 The isolation and metabolism of brown fat cells. Journal of Biological Chemistry 242 1887-1894.

Fernández-Galaz C, Fernández-Agulló T, Pérez C, Peralta S, Arribas C, Andrés A, Carrascosa JM \& Ros M 2002 Long-term food restriction prevents ageing-associated central leptin resistance in Wistar rats. Diabetologia 45 997-1003. 
Ferrannini E, Vichi S, Beck-Nielsen H, Laakso M, Paolisso G, Smith U \& European Group for the Study of Insulin Resistance (EGIR) 1996 Insulin action and age. Diabetes 45 947-953.

Ferré P, Leturque A, Burnol AF, Penicaud L \& Girard J 1985 A method to quantify glucose utilization in vivo in skeletal muscle and white adipose tissue of the anesthetized rat. Biochemical Journal 228 103-110.

Fink RI, Kolterman OG, Griffin J \& Olefsky JM 1983 Mechanisms of insulin resistance in aging. Journal of Clinical Investigation 71 1523-1535.

Fink RI, Wallace P \& Olefsky JM 1986 Effects of aging on glucose-mediated glucose disposal and glucose transport. Journal of Clinical Investigation $\mathbf{7 7}$ 2034-2041.

De Fronzo RA 1981 Glucose intolerance and aging. Diabetes Care 4 493-501.

Frühbeck G, Gómez-Ambrosi J, Muruzabal FJ \& Burrell MA 2001 The adipocyte: a model for integration of endocrine and metabolic signaling in energy metabolism regulation. American Journal of Physiology 280 E827-E847.

Gabriely I, Ma XH, Yang XM, Atzmon G, Rajala MW, Berg AH, Scherer P, Rossetti L \& Barzilai N 2002 Removal of visceral fat prevents insulin resistance and glucose intolerance of aging. Diabetes 51 2951-2958.

Goodman MN, Dluz SM, McElaney MA, Belur E \& Ruderman NB 1983 Glucose uptake and insulin sensitivity in rat muscle: changes during 3-96 weeks of age. American Journal of Physiology 244 E93-E100.

Hakimi P, Johnson MT, Yang J, Lepage DF, Conlon RA, Kalhan SC, Reshef L, Tilghman SM \& Hanson RW 2005 Phosphoenolpyruvate carboxykinase and the critical role of cataplerosis in the control of hepatic metabolism. Nutrition and Metabolism 233.

Hanson RW \& Reshef L 1997 Regulation of phosphoenolpyruvate carboxykinase (GTP) gene expression. Annual Review of Biochemistry 66 581-611.

Kiens B 2006 Skeletal muscle lipid metabolism in exercise and insulin resistance. Physiological Reviews 86 205-243.

Kraegen EW, Saha AK, Preston E, Wilks D, Hoy AJ, Cooney GJ \& Ruderman NB 2006 Increased malonyl-CoA and diacylglycerol content and reduced AMPK activity accompany insulin resistance induced by glucose infusion in muscle and liver of rats. American Journal of Physiology 290 E471-E479.

Lara-Castro C, Luo N, Wallace P, Klein RL \& Garvey WT 2006 Adiponectin multimeric complexes and the metabolic syndrome trait cluster. Diabetes $\mathbf{5 5}$ 249-259.

Levy JR, Davenport B, Clore JN \& Stevens W 2002 Lipid metabolism and resistin gene expression in insulin-resistant Fischer 344 rats. American Journal of Physiology 282 E626-E633.

Li H, Matheny M, Nicolson M, Tümer M \& Scarpace PJ 1997 Leptin gene expression increases with age independent of increasing adiposity in rats. Diabetes 46 2035-2039.

Molero JC, Martínez C, Andrés A, Satrústegui J \& Carrascosa JM 1998 Vanadate fully stimulates insulin receptor substrate-1 associated phosphatidyl inositol 3-kinase activity in adipocytes from young and old rats. FEBS Letters 425 298-304.

Molero JC, Pérez C, Martínez C, Villar M, Andrés A, Fermín Y \& Carrascosa JM 2002 Activation of MAP kinase by insulin and vanadate in adipocytes from young and old rats. Molecular and Cellular Endocrinology 189 77-84.
Muse ED, Obici S, Bhanot S, Monia BP, McKay RA, Rajala MW, Scherer PE \& Rossetti L 2004 Role of resistin in diet-induced hepatic insulin resistance. Journal of Clinical Investigation 114 232-239.

Narimiya M, Azhar S, Dolkas CB, Mondon CE, Sims C, Wright DW \& Reaven GM 1984 Insulin resistance in older rats. American Journal of Physiology 246 E397-E404.

Nishimura H, Kuzuya H, Okamoto M, Yoshimasa Y, Yamada K, Ida T, Kakehi T \& Imura H 1988 Change of insulin action with aging in conscious rats determined by euglycemic clamp. American Journal of Physiology 254 E92-E98.

Pérez C, Fernández-Galaz C, Fernández-Agulló T, Arribas C, Andrés A, Ros M \& Carrascosa JM 2004 Leptin impairs insulin signaling in rat adipocytes. Diabetes 53 347-353.

Rangwala SM, Rich AS, Rhoades B, Shapiro JS, Obici S, Rossetti L \& Lazar MA 2004 Abnormal glucose homeostasis due to chronic hyperresistinemia. Diabetes 53 1937-1941.

Rowe JW, Minaker KL, Pallota JA \& Flier JS 1983 Characterization of the insulin resistance of aging. Journal of Clinical Investigation $\mathbf{7 1}$ 1581-1587.

Satch H, Nguyen A, Miles PDG, Imamura T, Usui I \& Olefsky JO 2004 Adenovirus-mediated chronic 'hyper-resistinemia' leads to in vivo insulin resistance in normal rats. Journal of Clinical Investigation 114 224-231.

Smith U 2002 Impaired ('diabetic') insulin signaling and action occur in fat cells long before glucose intolerance: is insulin resistance initiated in the adipose tissue? International Journal of Obesity 26 897-904.

Steppan CM, Balley ST, Bhat S, Brown EJ, Banerjee RR, Wright CM, Patel HR, Ahima RS \& Lazar MA 2001 The hormone resistin links obesity to diabetes. Nature 409 307-312.

Villar M, Serrano R, Gallardo N, Carrascosa JM, Martínez C \& Andrés A 2006 Altered subcellular distribution of IRS-1 and IRS-3 is associated with defective Akt activation and GLUT4 translocation in insulin-resistant old rat adipocytes. Biochimica et Biophysica Acta 1763 197-206.

Wang Z, lv J, Zhang R, Zhu Y, Zhu D, Sun Y, Zhu J \& Han X 2006a Co-culture with fat cells induces cellular insulin resistance in primary hepatocytes. Biochemical and Biophysical Research Communications 345 976-983.

Wang Y, Lam KSL, Chan L, Chan KW, Lam JBB, Lam MC, Hoo RCL, Mak WWN, Cooper GJS \& Xu A $2006 b$ Post-translational modifications of the four conserved lysine residues within the collagenous domain of adiponectin are required for the formation of its high molecular weight oligomeric complex. Journal of Biological Chemistry 281 16391-16400.

Received in final form 2 April 2007

Accepted 13 April 2007

Made available online as an Accepted Preprint 19 April 2007 